\title{
Socialization and Child Rearing Practices Among Nigerian Ethnic Groups
}

\author{
Ajayi, Johnson Olusegun Ph.D
}

\author{
Ekiti State University, Ado-Ekiti, Nigeria. \\ delight_top@yahoo.com \\ Owumi, Benard \\ Department of Sociology \\ University of Ibadan, Ibadan, Nigeria \\ bowumi@yahoo.com
}

\section{Doi:10.5901/ajis.2013.v2n2p249}

\section{Abstract}

Children are socialized into adult roles in society through the process of socialization particularly through the family which is the first contact point of any child into the open world of human relations. Socialization forms differ from one society to the other, in Nigeria there are three major ethnic groups in addition to about two hundred and forty seven minor ones, the pattern and forms of socialization among these ethnic nationalities differ. Ethnic identities and loyalty are built up in children in Nigeria based on these different cultural settings. Divergence in political and social relations including ethnic bigotry experience in the country in contemporary time has its root embedded in the differentiation existing in the nature and nurture of children at the formative stage of their lives. This paper examines the patterns of socialization and child rearing found among the various ethnic groups in Nigeria with a view to identifying lines of symmetry for the promotion of unity and oneness that will engender rapid and sustainable development in the country.

Keywords: Nigeria, Children, Ethnic Identity, Socialization, Sustainable Development

\section{Introduction}

Socialization can simply be defined as the process of learning and practicing the culture of a given society by both the young and the adult members, it is the way of acquiring the specific prescriptions and proscriptions of standardized practice of a given society. When a child is born he or she is gradually taught and introduced to the culture of his or her society by the parents and the significant others within his or her family, this is otherwise referred to as primary socialisation. Without stress consciously or unconsciously the baby learns gradually such things as the mode of greetings, dressing, eating, and other ways of relating and associating with members of his or her society in an organized and orderly manner. Like it has been defined above socialization is not limited to the learning experiences of the young child but also the adult members. The adults may have to learn some basic skills and rules that have to do with the new status they occupy in a social group. Learning itself is a continuous process in human life. Each new day brings with it new experience that may also need new response that must be learnt in a special way. For example the introduction of a new technology demands a change from the old pattern to the new enabled through learning so as to adapt to the new pattern.

Essentially socialization can be looked at from two viewpoints: that of the society and that of the individual. To the society, socialization is the process of fitting new individuals into an organized way of life and teaching them the society's cultural traditions. Socialization transforms the raw human animal into a human being capable of rational actions with others in the society. As a result of that transformation most babies grow up into fully functioning social beings, able to use the language of their parents and competent in their society's culture. The baby grows and become familiar with the total ways of life of his/her people with nothing strange to him/her. Though each new day, brings into consciousness new experiences. That must be learnt either consciously or otherwise. It is upon the basis of what is learnt and internalized that the child relate with the outside world. Perceiving others behaviour and reflecting on same and also respond on the basis of his understanding. "Biological heredity," says Ogburn and Nimkoff (1950) "ushers the infant actor on to the stage 
which physical environment, the group, and culture have set. The dramatic action now begins and the new babe is gradually transformed into a social person. The term used by sociologist to designate this transformation is socialization"

Looking at the new born baby as a new actor, one can see without doubt that he possesses a number of organic powers or traits making up what is together called Organic Heritage $[\mathrm{O} . \mathrm{H}]$ factor sometimes known as the Original Nature or Original Endowment. This dynamic power or forces make up his arsenals with which he begins his fateful expedition upon the sea of life

The most highly developed trait in this organic heritage is the reflex, consisting of a stimulus-response arc made up of the familiar affector-connector- effector sequence. In other words when confronted by certain stimuli, regular behaviourism like breathing, sucking, swallowing, sneezing, vomiting etc naturally follow. These can, of cause, be conditioned; they need no learning to perform [Ogburn and Nimkoff, 1950].

\section{Socialization and Processes of Learning}

A child apparently possesses no human nature at birth; at best he is merely a new homo sapien with human nature potentials that need to be cultivated through the process of socialization. Smith [1953] has this to say about a new born baby:

\footnotetext{
"You came into the world a polymorphous perverse little ape with billions of biological evolution precipitated, so to speak in your dimpled organism. You came naked, without shame, without language, food habits or manual dexterity, ideas or religious faith, without respect for law and order, without any discernible admiration.... You came with no higher desires than to have your capacious belly filled with milk and your somatic and viscera itches scratched by loving hands'
}

It has been expressed in literature that new born babies minds are just like a tabula rasa an empty slate upon which the society write its norms and values hence as said above socialization becomes the process through which the new born baby acquires group norms, habits and ideals. However, there are four features of this process of learning group values. These are language, suggestion, imitation and identification. A brief description of these four features is crucial.

\subsection{Language}

Language is the medium of social intercourse. It is the means of cultural transmission. At first the child utters some random syllables which have no meaning, but gradually he comes to learn his mother-tongue.

\subsection{Suggestion}

Suggestion is the process of communicating information, which has no logical or self-evident basis. It is devoid of rational persuasion. It may be conveyed through language, pictures or some similar medium. It influences not only behavior with others but also one's own private and individual behavior. In trade, industry, politics, education and every other field people acquainted with psychological facts make use of suggestions to have, their ideas and notions accepted by other people and to make the latter behave according to their wishes. In fact, propaganda and advertising are based on the fundamental psychological principles of suggestion.

The suggestibility of the child is greater than that of the adult because in childhood he is devoid of maturity and reason. The suggestibility of an individual decreases with an increase in his maturity and mental level. It may be however necessary to keep in mind that there can be a difference in the suggestibility of children belonging to different society and also the same society. There are several external and internal conditions, which enhance suggestibility. Thus, temperament, intellectual ability, ignorance, inhibition, dissociation, emotional excitement and fatigue are some of the internal conditions of suggestibility. Among the external condition, mention may be made of group situation, prestige of the suggested and public opinion.

\subsection{Imitation}

According to Tarde cited in Martindale [1970 p.307] "Imitation or repetition, accounts for the transmission, constancy, and spread of social forms." Imitation can be said to be the act of copying by an individual of the actions of other. Thus when 
the child attempts to walk impressively like his father swinging a stick and wearing spectacles he is imitating. Imitation may be conscious or unconscious, spontaneous or deliberate, perceptual or ideational. The person imitating performs exactly the same activity as the one being performed before him by the person he is imitating. Imitation therefore, is the main factor in the process of socialization of the child. Through it he learns many social behavior patterns. It is because of the tendency to imitate that children are so susceptible to the influence of their parents and friends whose behavior they imitate indiscriminately.

\subsection{Identification}

In his early age, the child cannot make distinction between his organism and environment. Most of his actions are random. They are natural reaction of which he is not conscious. As he grows in age, he comes to know of the nature of things, which satisfy his needs. Such things become the object of his identification. Thus, the toy with which he plays, the picture book, which he enjoys or looking and the mother who feeds him become the object of his identification. The speed and area of identification increase with the growth in age. Through identification he becomes sociable.

\section{Agents of Socialization}

The principal agents in the socialization process are the significant others most especially the parents and the siblings of the ego, the teachers, peer groups, and any others close to him. There are also the mass media, both print and audiovisual from where he picks values, norms and ideas about the larger society outside his home base with which to interact with and belong to the social system..

\subsection{The Family}

The family is the first point of contact with the outside world by any child; here the basic tools with which he has to deal with the society and future life are passed to him. It here he learns good or bad morals as the case may be. He gets fixed up into the social strata by being a member of a family. The parents and other siblings are the representative of the larger society from whom the young first learns the appropriate behaviour patterns, attitudes, values, norms, mores and the folkways of the society. Family types differ from one social setting to the other we have the nuclear family system and the most practiced extended family structure in Nigeria, the interpersonal relations within each of these groups may either be authoritarian or laissez-faire or egalitarian all these are ingenious factors that significantly influence the socialization process and development of self by any child resulting into differences in behaviour and consequently in personality types in diverse cultures. The control and direction of its numerous children according to Otite and Ogionwo[2006] require not only the supervision and regulation of the parents alone but also of all other significant others of the extended family.

\subsection{The School}

From the school the child obtains skills with which he arms himself to interact with the social world. The teacher replaces the parents giving instructions, directing, and ordering the taught process of the child and helping him to think logically. Examples are given to enable the learner think the way the teacher wants. In this manner regular imitation of the teacher and rehearsing what the child has been taught and assimilating same equips him for eventual role he is expected to play in the larger society and in his family. Here also he internalizes values of punctuality, drudgery, hard-work, independent decision making and mastery over his tasks and profession.

\subsection{The Peer Groups}

The child also learns a lot from his peers, the group to which a child belongs is a measure of his social or anti-social behaviour. In schools and religious houses children want to join the happening groups in order to exercise their hidden prowess on a lot of social issues. He displays an unalloyed loyalty to the group that offers him voice, recognition and protection. He participates in group activities and in its values and dis-values thereby becoming self-conscious. Group identification and loyalty for him becomes intense psychological actualities, of a trans-rational nature. A conflict between groups brings about intensification and overwhelming high degree of loyalty, developing esprit de corps or morale 
[Martindale, 1970 p.201]. Although peers can be a positive force of influence seen in such things as sports, girls guide, scouting, faith groups and other positive influences, they are also of negative influence. The most detrimental impacts of this are drug and alcohol use, premature sexual engagements and other social proscribed behaviours. At school also peers influences develop in the area of academic achievement. Being ostracized and chastised for "being smart" is often a common burden placed on the otherwise high-achieving students, particularly the marginal minority students. At this point in a student's socialization process teachers, parents, and other adults role models play a significant role in shaping the lives of the young in society.

\subsection{Religion}

Religion is another scintillating agent of socialization; values about morality, truth and just living are both taught in religious gatherings. There are values about what is holy treated with awe and reference and what is profane which might be handled with laxity. In its entirety religion provides the child with a code of conduct. Most of the acts the society prohibits or prescribes in terms of dressing, friendship, food, sex and sexuality and alcohol derive from the religion practiced by a people.

\subsection{The Mass Media}

The mass media has an enormous influence on the young and even the adult minds. The introduction of the internet has added to the role of the television in shaping the lives of people in present day society. The culture portrayed by the mass media emphasizes glamour, sexual gratification and promiscuity, pornography, homosexuality and lesbianism, comedic vulgarity, violence and immediate gratification of needs. It is often said that what a man watches or sees has the potential of sticking to the brain than what he hears. Hence the audio-visual system of dissemination of information plays a very significant role in shaping and reshaping, moulding and remoulding of the lives of both the young and adult members of the society.

\section{Types of Socialization}

There are five essential types of socialization we can find in any society; these are infant socialization, anticipatory socialization, rite of passage, the re-socialization and induction/ orientation. These will be discussed one after the other thus:

\subsection{Infant Socialization}

This is an attempt to instruct infants of the way of life of the people to which he belongs. This instruction involves such things like the way of greeting, eating, dressing, relating with elders and people of the opposite sex within the family and outside of it. Alubo [2012] posits that this form of socialization is purely informal. When there is serious mistake by the children they are looked at disdainfully, jeered at or spanked. The child behaviour is monitored regularly to make sure the boy or girl adhered to the instructions of his parents. It is not uncommon to hear a father or mother telling the young to always remember the son or daughter of whom he or she is when occasion warrants the child acting outside and far away from the parents. Riesman in Martindale, 1970 p.429 says in an "inner-directed" society a new pattern of conformity resting on internalized controls appears. The parent is in control rather than the extended family.

\subsection{Anticipatory socialization}

This is socialization in anticipation of the status someone might occupy in future. It is common to see little kids acting out some positions like father, mother, preacher, footballer or a cook, apparently they may or may not occupy some of these positions, but the fact is they acknowledge the existence of these statuses.

\subsection{Induction}

The newly employed in any organization be it public or private need to go through induction whereby specific skills related to the work and roles he is expected to play 


\subsection{Rite of passage}

This is involves rituals or ceremonies performed to mark the movement from one stage of life to the other among the llogbo people of Ekiti state there are different rites performed for the youths moving up to the Awere the warrior group that keep watch over the town and responding to any imminent threat from external and internal aggressors. Birth, puberty, marriages and funerals are the most common rites of passage celebrated in llogbo community. Becoming an elder may be formally observed in retirement ceremony or in handling over of responsibilities to a son or daughter. Rite of passage usually have three basic elements [a] a separation phase in which the person sheds his or her former status [b] a transition phase [c] an incorporation phase that confirms the new position. Separation may by symbolized in ceremonies that treat the individual's passage out of the prior status as ritual death and incorporation into the new status as ritual rebirth. The ritual apparently makes clear which old rights and duties have been discarded and which new ones have been acquired. In Ogori-Magongo of Kogi State young marriageable girls are specially paraded in the open street half nude in a big ceremony to tell anyone that cares that these girls are moving from their former not ready for marriage status to the ready for marriage. In Akwa-lbom and part of Cross River states young girls are held up in fattening rooms to mark passage to adulthood. In the fattening rooms these girls are taught and trained to cook delicious meals, care of the baby, husband etc.

\subsection{Re-Socialization}

This is a type of socialization that marks a sharp break from the former status and a learning of another quite different from what one knows in the past. Re-socialization is common in prisons and other total institutions. The day an offender enters the prison he becomes relatively separated from the outside world, his life is regulated, and daily activities are tightly scheduled without his participation in the design of the activities. The prison inmates take a different accommodation, special dress with number tag. He is virtually dispossessed of self and at all times he is expected to respond to the dictates of the warders.

\section{Importance of Socialization}

Socialization is important because we are social animals. If you can't interact and socialize with those around you, life will be extremely difficult. Not knowing the rules of behavior for your society and culture can create a lot of problems. For example in Nigeria culture, smiling is a sign of friendliness depending on the circumstance but generally it is considered polite, but in other cultures smiling at someone might be considered rude or a sign of weakness.

Social and intelligible interpersonal relations occur among the Homo sapiens thought to be rational animal, the social animal and also the anxious animal, but looking critically at the cases of people who have not gone through the socialization process - the so called 'feral children' - it becomes very clear that without socialization we have little capacity to be human [c.f. Chinoy, 1967; Bierstedt, 1970 p125]. There would have been whole lots of irrationality without socialization and culture the sets of established ways of doing things developed in a society wouldn't have been transmissible.

Learning the ways of life of a people helps in integrating individuals to the social group to which they belong. For example a new born baby is taken through the culture of his group by the parents teaching and directing him to do those things that are acceptable to his society. A deviant therefore can be said to be for some reason inadequately socialized.

Basic disciplines ranging from toilet habits to the more complex system are thought through the process of socialization, while undisciplined behavior could be a response to an impulse. It ignores future consequences for immediate advantages which in fact may be upsetting. Regulated behavior postpones rewards or substitutes other benefits for the sake of a long term goal or to win social approval. Discipline could so be learnt, thoroughly internalized, that they even modify the person's physiological reactions. For instance many people wake up early whether they like it or not, and many are physically unable to perform acts that are socially prohibited. A person may become ill after eating tabooed meal.

Every society instils a variety of aspirations in its members, these aspirations match the status individuals will occupy because of their age, sex, group membership or family background. Thus in pre literate society a hunter instilled in his son the desire to be a good hunter, a good and faithful participant at deity worship, a leader of hunting expeditions 
in his mature years, a dependable and strong man in his society. His daughter was brought up to be pious worshipers of the gods, a diligent and capable housekeeper, and a devoted wife and mother.

Socialization is so important to man based on the individuals identities provided largely through the aspirations it encourages or discourages. An identity is a self-concept built up over a lifetime. The son of a chief or a poor man wakes up to see himself acting out the status he occupies in his society. In Nigeria children are socialized early to know who he is, where he comes from and what group he belongs, the religion his group practices etc. All these shape the identity of individuals within the whole. We are practically the way we are partly because of other people's reactions to us and to what we do. We are constantly picking this feedback and incorporating it into our sense of self, thus identity is built up through interpersonal relations. It is a social construction as well as a personal certainty.

Socialization is central to man's life because it teaches roles, the rights and duties attached to particular social statuses. The little boy that acts as husband in folk play is beginning to learn the content of the father role. Apprenticeship both socializes the new worker to an occupational role and teaches the skills needed in that job. The most important roles usually become part of the person's identity. Thus answers to who am I? Question usually includes the person's main roles, for example, a family role [husband/wife] and occupational role [clerk/lawyer].

By the acquisition of skills individuals get fixed into society. In simple societies according to Broom and Selznick [1973] traditional practices are handed down from generation to generation and are usually learned by imitation and practice in the course of everyday life whereas in advance societies, inculcating the abstract skills of literacy through formal education is a central task of socialization. However the individual who lacks appropriate skills is economically unproductive, relegated to the margins of society, and likely to feel alienated from both the society and himself. In other words formal education has become imperative for effective socialization into the prevailing social order.

\section{Child Rearing In Nigeria}

In Nigeria children are highly valued. They are seen as a wonderful blessing from God after marriage, so the care for them is taken seriously. When a woman puts to bed she and the baby goes into confinement, she breast feeds, carry the child on the back and sleep with the child. It has been observed that taboos against pregnant women eating nutritious foods, delivery in traditional healers' homes, unhygienic care of the umbilical cord, hierarchical or gender biased food distribution have a debilitating effect on the mother and the baby's health[ [Onigbodun and Olatawura, 2008]. This pattern or practice has malnourished the mother and subsequently the baby leading to high rate of infant and maternal morbidity and mortality witnessed from time to time.

Nigeria being a patriarchal society, men enjoy hegemony over decision making on important issues, like the care of children. In the extended family system, close ties exist between men (husbands) and their parents as well as other relatives such that men, in conjunction with their parents, take most family decisions (Babalola, 1991). As observed by Orubuloye (1995:140) "in much of Nigerian society, the great majority of people still live in extended families either with or in close proximity to relatives". This facilitates stronger influence of relatives on the life and decision of husbands.

The way a child is reared greatly influences the child's development mentally, socially, emotionally, physically and morally. However in recent times, educational institutions such as Nursery \& Day care centres have taken over the responsibility of rearing children in Nigeria. Judging from the ways and manners Nigerians handle their children, it appears we are still in the dark ages when children were accepted to be born sinful and evil and needed to be exorcised through punishment or that they are miniature adult that has to carry out our instructions and be molded into the image we carve out for them. This may be the reason behind our violence attitude to children accusing them of witchcraft and wizardry. Some of Nigeria's child rearing practices could be categorized as child abuse [Idogo, 2001].

The predominant cultural belief is that children must be submissive to elders therefore behavior not in conformity with this is punished. In Nigeria, children experience harsh treatment from their care - givers including their parents. Under normal circumstances, the cry of a baby should attract attention, love and care; instead it attracts aggressive responses from care-givers at home, in day-care centers and in schools. The baby goes through harmful rituals on the eight day of his birth even though elaborate ceremonies are conducted for naming of children on the eight day in most communities in Nigeria. The newly born is exposed to noise and more importantly he or she experiences the taste of alligator- pepper, raw palm oil and other materials as part of the rituals of the ceremony; welcoming the baby to the difficulty world.

Circumcision for either baby boy or girl is done on that same eight day depending on the prevailing culture of the people. The female circumcision (Female Genital Mutilation - FGM), is still practiced in some communities in Nigeria as 
culture commands. The home environment provides the raw material for the growth and development of the brain capacity. In a home where domestic violence exists, it will have a detrimental effect on the child's brain, in Teicher (2002), teachers provide an in-depth overview of studies suggesting that early maltreatment can have enduring and measurable effect on a child's developing brain, diminishing growth and reducing activity in key areas.

The traditional childrearing practices in Nigeria are communal within the extended family system or lineage, and the costs of raising children are not borne solely by the biological parents. Very close relatives also share the costs of rearing children, in terms of emotion, time, finance and other material support, since all children together comprise the strength of the lineage. Studies have indicated that the ubiquity of the extended family structure is the pillar supporting such childrearing practices (Fapohunda and Todaro, 1988; Isiugo-Abanihe, 1985; 1991).

In Nigeria the extended family structure, which comprises close relatives other than a married couple and children, who live either in the same household or in a close and continuous relationship with one another, are generally in vogue. Nukunya (1992: 47) conceives the extended family as a "social arrangement in which an individual has extensive reciprocal duties, obligations and responsibilities to his relations outside his nuclear family". Within the framework of this family structure, series of childrearing practices are maintained. Right from birth, surrogate mothers, maybe either mother-in-laws or sister-in-laws from either the husband's or wife's family, make themselves available to assist in caring for the new born baby and the nursing mother (Fapohunda and Todaro, 1988).

This practice lessens the emotional burden a nursing mother goes through during the early period of childrearing, and by extension, encourages men to maintain high fertility goals in a society where more children is perfectly rational. In a related sense, various ways of child fostering exist among relatives and nonrelatives - but child fostering among members of kinship group is more predominant in Nigeria. Within the sphere of looking after children, they are often transferred from their biological homes to their relative homes - the homes of uncles, aunts, cousins, etc., - where they are raised (Isiugo-Abanihe, 1985).

The strong family ties existing among brothers, sisters, cousins, etc., even when they are married, facilitate this transfer and sharing of children. Childrearing costs are either totally transferred or shared within the extended family system through this traditional mechanism. Again, through this practice, men are somehow relieved of some burden since the emotional, material and financial cost of raising children are shared or nearly completely transferred to others. Within this system, young men sometimes get married and keep their wives and children back at home while they maintain a separate home in the city where they work.

It was therefore mandatory for extended family members to share the burden (or cost) of sustaining such a woman (regarded as a wife to all in the family) and her children. Secondly an important element of the extended family structure is polygyny, with men being encouraged to marry two or more women at the same time. Both co-residential polygyny and serial-monogamy are common practices in Nigeria (National Population Commission, 1998). Couples in polygynous homes typically maintain separate purse and consequently share childrearing cost disproportionately, women often being made to bear more of the cost of raising and caring for children. Because men are not the main bearers of the cost of their reproductive action, even though they are the main beneficiaries, a large family size is seen as desirable.

Nigeria is still largely an agrarian economy, and due to low level of technology prevailing in agriculture and the communal land tenure in practice, especially in the rural areas, emphasis has been strongly on large family size (Orubuloye, 1995). In most cultures only male children are allowed to share in family land holdings - this is facilitated by the prevailing extended family structure. Since farming is central to economic life and men are the chief decision-makers, the most economically rewarding reproductive goal a man could pursue is large family size. It is against this background that couples dread barrenness and until a "good" number of male children are born, extended family members exert pressure, which may culminate into the man marrying another wife (Wusu, 2001). Of course, emphasis was on quantity and not quality of children, raising children who are to engage in farm work would not be as expensive as giving them quality education.

\section{Conclusion and Recommendation}

Effective socialization and well articulated child rearing practices are a panacea to rapid and efficient developmental activities in any modern and civilized society, because development itself is all about people. In some areas in the country children are still used in hawking wares during the time they are expected to be in school despite government policy on universal basic education [UBE] and education for all [EFA]. They are trafficked across Nigerian borders; some are used 
as mere beast of burden, and still some are carelessly handled by parents and care givers alike without the necessary emotional love and care they need for all round physical and mental development.

Proper upbringing of children should be encouraged in Nigerian society, the Bible has this to say: train a child the way he should go when he grows old he will never depart from it, efficient socialization of the child will lead to conformity to societal norms and values giving room for a well organized, morally upright, orderly and well integrated society. Parents should create time to be with their children so as to give them the trainings and nurture required of them to equip the children for future roles they are expected to play in the overall society. Proper behavior is a function of good basic home training, an antidote to bad peer influence, a precursor and foundation upon what other socializing agents build upon.

Efficient monitoring should be encouraged for all government policies on education in Nigeria so that the children will benefit from these policies and get them ready to occupy the status expected of them as those in front grow old.

\section{References}

Alubo, O. 2012. Sociology: A concise Introduction . Jos: ICHEJUM Press.

Babalola, Stella. 1991. The Educated Wife and Decision Making: The Study of a Professional Group. LASU Journal of Humanities, 2 (1 \& 2):132-142.

Bierstedt, R. 1970. The social order third edition. India:McGraw-Hill, Inc.

Broom, L and Selznick P. 1973. Sociology: A text with adapted Readings, fifth edition. New York: Harper and Row, Publishers. Inc.

Chinoy, E. 1967. Society: An Introduction to Sociology. University of California: Random House.

Fapounda, R. Eleamor and Todaro, P. Michael. 1988. Family structure, implicit contracts, and the demand for children in Southern Nigeria: Population and Development Review, 14 (4): 571 - 594.

Idogo, G. 2011. The effect of domestic violence on pre-school children in Nigeria. AfricanJournal of Education and Technology, Vol. 6 , No.1, pp10-15

Isugo-Abanihe, Uche C. 1985. "Child Fosterage in West Africa". Population and Development Review, 11 (1): 53-72.

Martindale, D. 1970. The Nature and Types of Sociological Theory. Great Britain: Routledge \& Kegan Paul Ltd.

Nukunya, G. K. 1992. Transition and Change in Ghana: An Introduction to Sociology. Accra: Ghana Universities Press.

Onigbodun, O.O \& Olatawura,M.U 2008. Child rearing practices in Nigeria: Implications for Mental Health. Nigeria Journal of Psychiatry Vol.6, No1 pp10-15

Orubuloye, I.O. 1995. The Demographic situation in Nigeria and Prospects for Fertility Transition: Journal of International Development, 7 (1): $135-144$

Otite, O. \& Ogionwo, W. 2006. An Introduction to Sociological studies. Ibadan: H.E.B Nigeria PIc.

Wusu, Onipede .2001. The Analysis of Childbearing and Childrearing in Nigeria: The Case of llogbo Community. Ibom Journal of Social Issues, 6 (2): 13-29. 